ISSN: 2238-8052

\title{
ABORDAGEM INTERDISCIPLINAR SOBRE A INFLUÊNCIA DA ZONA DE CONVERGÊNCIA INTERTROPICAL — ZCIT NO NORDESTE BRASILEIRO
}

\author{
INTERDISCIPLINARY APPROACH ON THE INFLUENCE OF THE INTERTROPICAL \\ CONVERGENCE ZONE - ITCZ IN THE NORTHEAST BRAZIL
}

\author{
Misael José da SILVA ${ }^{1}$ \\ Josiclêda Domiciano GALVÍNCIO ${ }^{2}$ \\ Valéria Sandra de Oliveira COSTA ${ }^{3}$
}

Artigo recebido em 04/11/2017 e aceito em 12/12/2017

Palavras-chave

Prática

interdisciplinar

Nordeste brasileiro

Ensino

Keywords:

Interdisciplinary

practice

Brazilian Northeast

Teaching

\section{R E S U M O}

A Zona de Convergência Intertropical (ZCIT) é um dos mais importantes sistemas meteorológicos atuando nos trópicos, ela é parte integrante da circulação geral da atmosfera. A ZCIT é o principal sistema de produção de chuvas do semiárido do Nordeste brasileiro. 0 trabalho ora apresentado está pautado na ausência de conhecimentos da população em geral, em especial de discentes do ensino fundamental e médio, sobre a importância e influência da ZCIT na região do Nordeste brasileiro. Através da problemática mencionada foi aplicada uma abordagem interdisciplinar sobre a ZCIT em uma turma do ensino fundamental. E com isso foi desenvolvido no aluno competências e habilidades no âmbito das interpretações de fenômenos climáticos e suas consequências para o meio antrópico, em especial a ZCIT. E para os professores revelou o quanto é significativo desenvolver novas posturas diante dos conhecimentos e abordagens em suas ações diárias, a fim de garantir a construção de um conhecimento globalizante e menos fragmentado como ocorre na contemporaneidade.

\begin{abstract}
A B S T R A C T
The Intertropical Convergence Zone (ITCZ) is one of the most important meteorological systems operating in the tropics, it is an integral part of the general circulation of the atmosphere and the main rainfall system of the semi-arid region of northeastern Brazil. The work presented here is based on the lack of knowledge of the population in general, and especially of primary and secondary school students about the importance and influence of the ITCZ in the region of the Brazilian Northeast. Through the mentioned problem, an interdisciplinary approach was applied on the ITCZ in a class of elementary education. And with this, the student was able to develop skills and abilities in the context of interpretations of climatic phenomena and their consequences for the anthropic environment, especially the ITCZ. And for the teachers revealed how significant it is to develop new postures in the face of the knowledge and approaches in their daily actions, in order to guarantee the construction of a globalizing and less fragmented knowledge as it happens in the contemporaneity.
\end{abstract}

\footnotetext{
${ }^{1}$ Mestrando do Programa de Mestrado Profissional em Rede Nacional para o Ensino das Ciências Ambientais da Universidade Federal de Pernambuco - PROFCIAMB-UFPE, Professor do ensino fundamental e médio da rede privada e pública, Recife-PE. E-mail: misaellogistica@hotmail.com (autor correspondente).

2 Professora do Departamento de Ciências Geográficas e do PROFCIAMB-UFPE, Universidade Federal de Pernambuco, RecifePE. E-mail: josicleda@gmail.com.

${ }^{3}$ Professora do PROFCIAMB-UFPE, CAPES/PNPD-PRODEMA, Universidade Federal de Pernambuco, Recife-PE. E-mail: costavso@yahoo.com.br.
} 


\section{INTRODUÇÃO}

A sociedade atual exige novas modalidades educacionais que promovam cada vez mais a democratização e dinâmica do saber. Nesse contexto, o ensino interdisciplinar se apresenta como uma ferramenta inovadora frente às ações menos descentralizadas do conhecimento. Esse tipo de ensino desempenha um importante papel no tratamento e acesso à informação que gera novos modos de expressão, de acesso e de participação na sociedade, sendo assim.

A prática interdisciplinar vem sendo amplamente divulgada no meio acadêmico e escolar, visto que são notáveis os seus benefícios em curto e médio prazo. Essa estratégia didática evidencia que o conhecimento humano é historicamente adquirido e não se subdivide em "caixinhas", e que deve ser concebido de forma heterogênea como um todo. Segundo Philippi Jr. et al. (2000) a interdisciplinaridade consiste num tema, objeto ou abordagem em que duas ou mais disciplinas intencionalmente estabelecem nexos e vínculos entre si para alcançar um conhecimento mais abrangente, ao mesmo tempo diversificado e unificado. No ambiente escolar prático há grandes dificuldades em se aplicar ações interdisciplinares, pois as disciplinas atuam perto, mas não juntas devido a vários motivos, entre eles, o contexto histórico das atividades humanas imposta pelo modelo economicista dominante. Entretanto, de acordo com Pires (1998) a interdisciplinaridade pode ser tomada como uma possibilidade de quebrar a rigidez dos compartimentos em que se encontram isoladas as disciplinas dos currículos escolares.

Diante disso, pode-se inferir também a quebra contínua e progressiva de velhos paradigmas educacionais e ou pedagógicos no seio escolar visto que, a interdisciplinaridade refere-se à formação integral do indivíduo na perspectiva da totalidade. Onde o ofício de ensinar na contemporaneidade requer habilidades, para despertar e satisfazer a curiosidade dos alunos e, ao mesmo tempo, ser direcionado e aberto a diferentes olhares, refletindo, de forma equilibrada no espaço coletivo de vivência. Portanto, foi proposta uma exposição interdisciplinar para os anos finais do ensino fundamental, abordando o tema mencionado, e o correlacionando com outras ciências de forma contextualizada, estabelecendo relações entre os conhecimentos, os aspectos socioambientais, políticos, culturais e tecnocientíficos numa ação dialética no âmbito da influência da Zona de Convergência Intertropical (ZCIT) sobre a região do Nordeste brasileiro.

\section{MATERIAL E MÉTODOS}

A proposta interdisciplinar foi apresentada ao corpo escolar que contribuiu com uma tempestade de ideias sobre a temática e as disciplinas que seriam envolvidas no projeto. Após 
discussão, as disciplinas escolhidas devido à disponibilidade dos professores foram matemática, ciências, português, Artes e Geografia.

A apresentação dos conteúdos foi realizada por todas as disciplinas em um período de seis horas aulas onde as três primeiras foram ministradas por professores de matemática, português/artes e ciências, as penúltimas aulas foram ministradas pelo professor de Geografia. Após a finalização das apresentações dos conteúdos programáticos, os discentes foram divididos em equipes e a partir do exposto desenvolveram um painel relacionando as influências, consequências e importância da ZCIT no contexto do Nordeste brasileiro. Concluído os passos acima, ocorreram apresentações de forma oral, onde todos os membros das equipes participaram demostrando suas impressões sobre a aprendizagem durante as aulas interdisciplinares.

Os recursos didáticos utilizados foram vídeos sobre a temática, reportagens de jornais e revistas (impressos e online), ilustrações, fotos e imagens de satélites, mapa mundo, papel, cola e tesouras. Como situações didáticas destacam-se, debates, trabalho em equipe, construção de um painel e exposição de conteúdo.

\section{RESULTADOS E DISCUSSÕES}

No nordeste brasileiro existem cerca de seis sistemas atmosféricos que produzem as precipitações, são elas, as frentes frias vindas do Sul; as ondas de Leste; os ciclones na média e na alta troposfera, as brisas terrestres e marítimas; as oscilações de 30-60 dias e a ZCIT. Segundo Cirilo et al. (2007) a ZCIT é formada pela confluência dos ventos alísios do Hemisfério Norte, (alísios de nordeste) e os do Hemisfério Sul, (alísio de sudeste) (Figura 1). A confluência resulta em movimentos ascendentes de ar com alto teor de vapor d'água. Ao subir na atmosfera, o vapor d'água se resfria e condensa dando origem ao aparecimento de nuvens numa faixa que é conhecida como tendo a mais alta taxa de precipitação do Globo Terrestre. Devido à sua estrutura física, ela tem se mostrado decisiva na caracterização das diferentes condições de tempo e de clima em diversas áreas da região tropical influenciando as precipitações nos continentes africano, americano e asiático. A faixa de convergência é facilmente reconhecida em fotos de satélites pela presença quase constante de grande nebulosidade na faixa intertropical, próximo à linha equatorial, conforme representa a Figura 2. 
Figura 1: Confluência dos ventos alísios do Hemisfério Norte e do Hemisfério Sul.

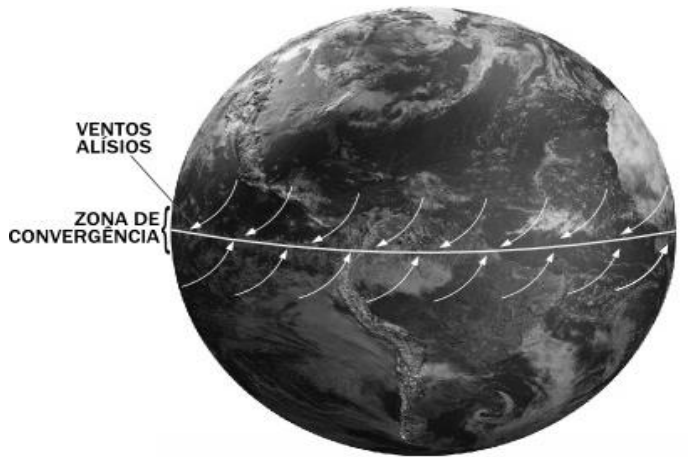

Fonte: $\underline{\text { http://brasilescola.uol.com.br/geografia/ventos-alisios.htm }}$

Figura 2: Banda de nebulosidade no centro da imagem representando a ZCIT.

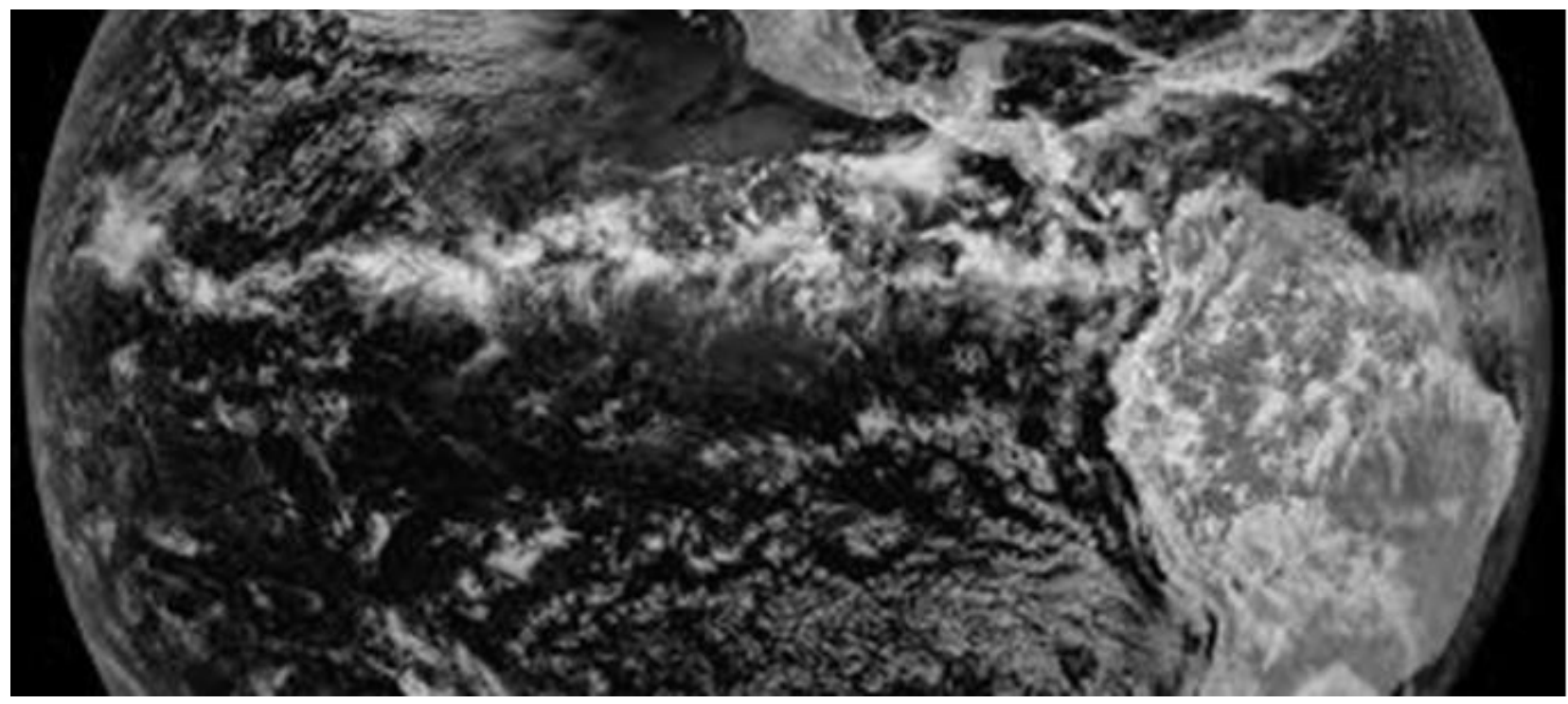

Fonte: wikiwand.com/pt/Zona_de_converg\%C3\%AAncia_intertropical

Parafraseando Mendonça e Danni-Oliveira (2007), essas massas de nuvens com largura de algumas centenas de quilômetros, que se forma devido à importante ascendência zonal apresenta céu bastante coberto por nuvens, principalmente do tipo cumuliformes que ocasionam expressivas precipitações. De acordo com Cirilo et al. (2007), a ZCIT, em geral, atua sobre uma região qualquer por um período de tempo superior a dois meses, ou seja, é um fenômeno tipicamente climático, e sua localização futura pode ser prevista com alguns meses de antecedência. Contudo, as chuvas intensas ocorridas em algumas áreas dentro da ZCIT, geralmente, só são previstas com poucas horas de antecedência e a melhoria da previsão desses sistemas depende de informações de altitude e de radar meteorológico. Ela provoca grande zona de instabilidade que oscila para norte e para sul, dependendo 
da época do ano sempre perto da faixa equatorial do Globo terrestre, sua intensidade depende da circulação geral da atmosfera bem como do aquecimento da superfície do Mar — TSM.

A ZCIT configura um divisor entre as circulações atmosféricas celulares que se localizam nas proximidades do Equador, sejam as células norte ou sul de Hadley. Ela é móvel, uma vez que se desloca durante o ano. A sua disposição diária e sazonal está condicionada a vários fatores, dentre os quais se destacam a continentalidade ou a maritimidade, o relevo e a vegetação (MENDONÇA; DANNIOLIVEIRA, 2007). Esse eixo acompanha o deslocamento aparente do Sol com um atraso de aproximadamente dois meses, em média. Na faixa do Atlântico/América do Sul, sua posição mais ao norte se dá em agosto-setembro quando alcança $15^{\circ} \mathrm{N}$, e sua posição mais ao sul acontece em marçoabril quando chega a $2^{\circ}$ S. Essas posições podem variar de cerca de $3^{\circ}$ a $4^{\circ}$ graus de latitude para norte ou para sul em alguns anos. Essa variação na posição do eixo médio da ZCIT está associada com a ocorrência de secas (posição mais ao norte) e chuvas acima da média (posição mais ao sul) (CAVIEDES, 1972). Tal fato é observado quando se considera que o pico de precipitação sobre o Nordeste ocorre exatamente na época em que a ZCIT atinge suas posições mais ao sul, tornando-se o sistema meteorológico mais importante na determinação de quão abundante ou deficiente serão as chuvas no setor norte do Nordeste do Brasil (Figura 3). Além de provocar nos dias atuais pesados aguaceiros, de caráter convectivo (JATOBÁ; LINS, 1996).

Figura 3: Localização mais ao sul da ZCIT provocando fortes chuvas no Norte e Nordeste do Brasil.

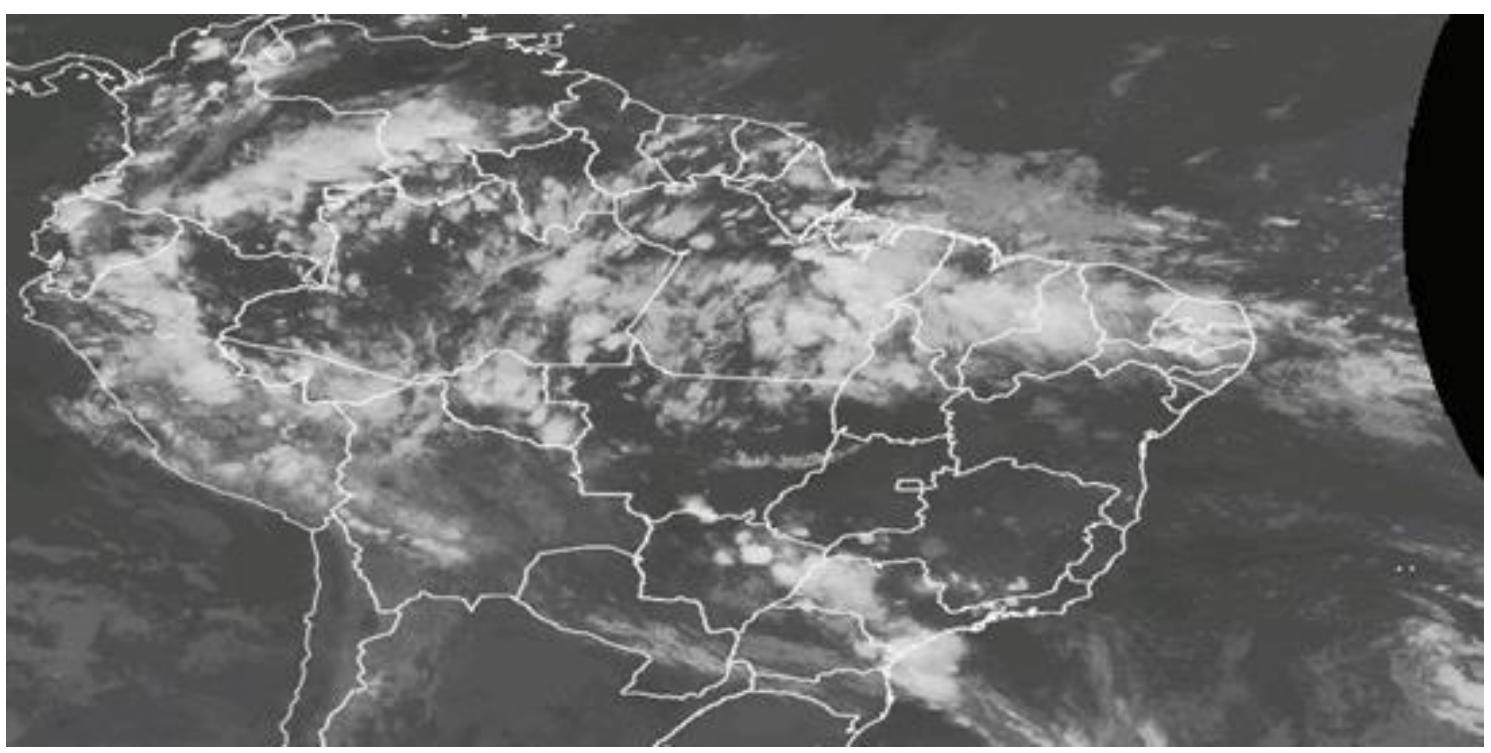

Fonte: https://www.climatempo.com.br/satelite/nde

O sistema ZCIT produz a maioria das chuvas na região semiárida e lá atua durante os meses de fevereiro a maio. No Sertão, o período chuvoso vai de dezembro a maio com máximos de precipitação durante fevereiro e março. No Agreste, o período chuvoso vai de fevereiro a julho com máximas de 
precipitação durante abril e maio (CIRILO et al., 2007). Entretanto, outros sistemas oriundos da ZCIT podem causar enchentes e inundações. Por outro lado, nos anos nos quais a ZCIT não atua nos meses de março e/ou abril, a região sofre com a falta de chuvas, principalmente no semiárido. De acordo com Jatobá e Lins (1996) nos anos em que o Atlântico Tropical Sul se encontra mais frio, os alísios austrais se intensificam como uma decorrência da maior expansão do Anticiclone Semifixo do Atlântico meridional, de onde partem em direção às baixas pressões equatoriais. Nessa situação, no semiárido dos estados do Ceará, Rio Grande do Norte, Paraíba e Pernambuco, instala-se a seca (Figura 4).

Diante das apresentações acima sobre a ZCIT, pode-se iniciar como ocorreu a prática interdisciplinar na escola. 0 ponto inicial se deu através do professor de matemática conceituando o índice pluviométrico, que registra a quantidade de chuvas por $\mathrm{m}^{2}$ em determinado local, relacionando que as chuvas se tornam catastróficas quando ocorrem precipitações em grande quantidade, em um tempo muito curto, sendo denominadas de torrenciais que provocam consequentemente alagamentos, enchentes e transbordamentos, principalmente nas grandes cidades (Figura 5). Foi mencionado ainda que quando as médias são baixas, provocam períodos de estiagem ou de secas ocorrendo quando o volume de precipitação é incapaz de repor a água retirada pelos índices de evapotranspiração (evaporação de massas líquidas e transpiração dos vegetais e animais) e pela demanda humana.

Figura 4: Posição mais ao norte da ZCIT inibindo as chuvas no Nordeste brasileiro.

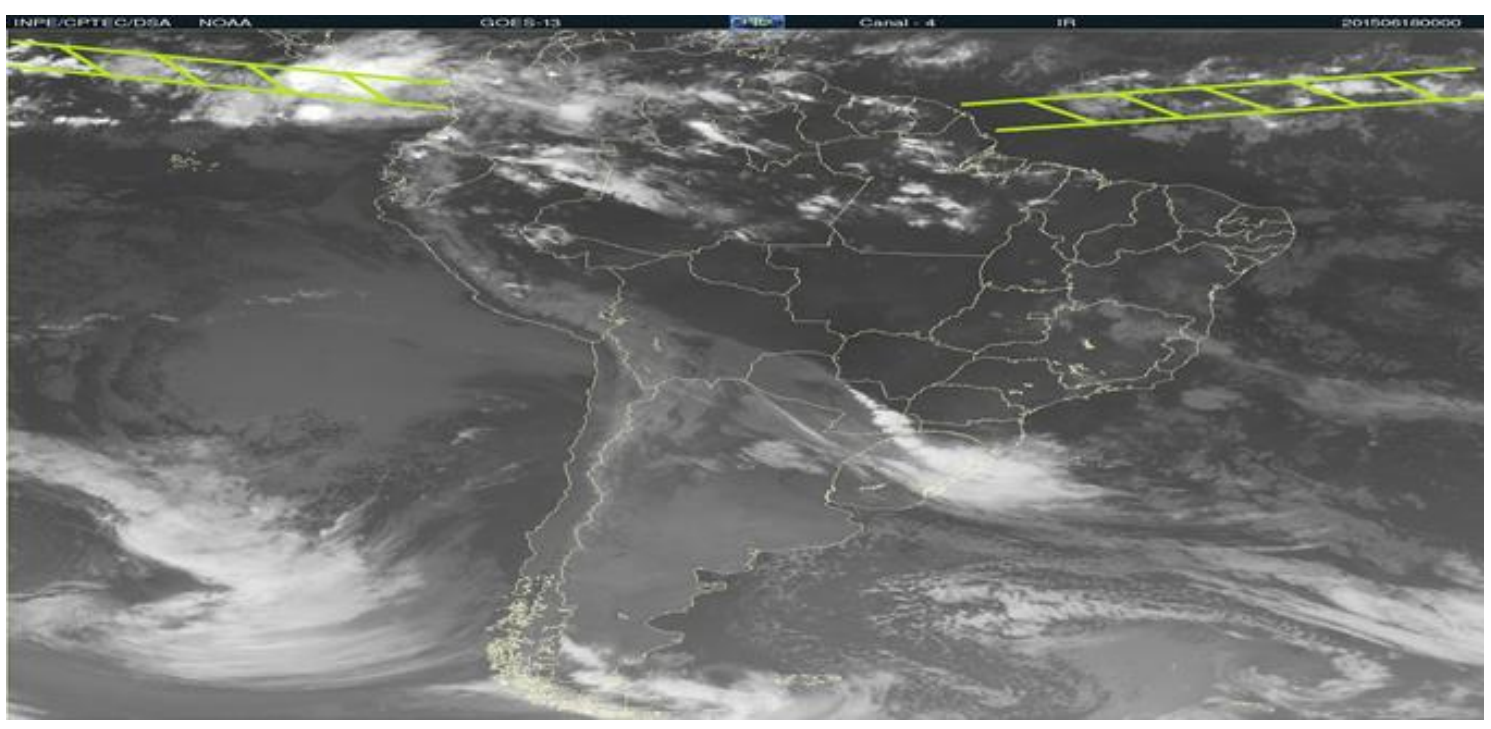

Fonte: http://meteosinotica.blogspot.com.br/2015/05/zcit.html. 
Figura 5: Apresentação realizada pelo professor de Matemática.

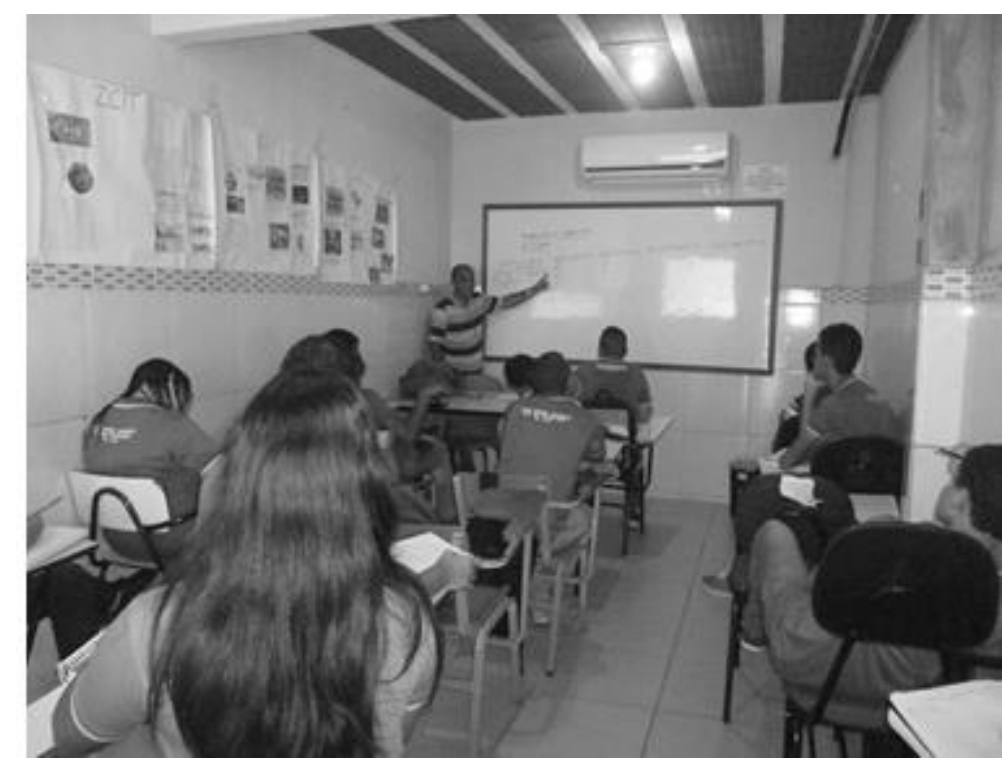

Fonte: Registro fotográfico de Misael Silva.

0 professor frisou que esses períodos de estiagem podem ocorrer pontualmente e afetar grandes áreas, em especial a região semiárida do Nordeste brasileiro, visto que apresenta os maiores eventos de seca, sendo influenciada, principalmente, entre outros fatores, pela ZCIT, quando ela se desloca mais ao norte diminuindo o volume de chuvas.

Foi levantado pelo professor de Geografia, este acompanhava e auxiliava os professores, que quando essa influência se associa às consequências do El Niño, as estiagens no Norte e Nordeste são intensas, já no Sul as chuvas são torrenciais. Baseado em dados estatísticos, o professor expos climogramas representando algumas médias históricas das precipitações dos últimos dez anos na região nordestina, finalizando assim sua prática.

$\mathrm{Na}$ aula posterior, a professora de ciências iniciou sua fala associando os climas a outros fenômenos, como altitude, relevo, maritimidade, continentalidade, densidade vegetal e evapotranspiração correlacionando-os a fatores climáticos como temperatura, umidade e pressão (Figura 6). Houve bastante questionamento por parte dos alunos a respeito desta última, que segundo Ferretti (2009) pode ser explicada como o movimento do ar e a manutenção de um gradiente de pressão horizontal, que funciona como a força motivadora para o ar se movimentar de áreas de alta pressão para as de menor pressão, e assim produzindo os ventos. 
Figura 6: Professora de Ciências em sua prática interdisciplinar.

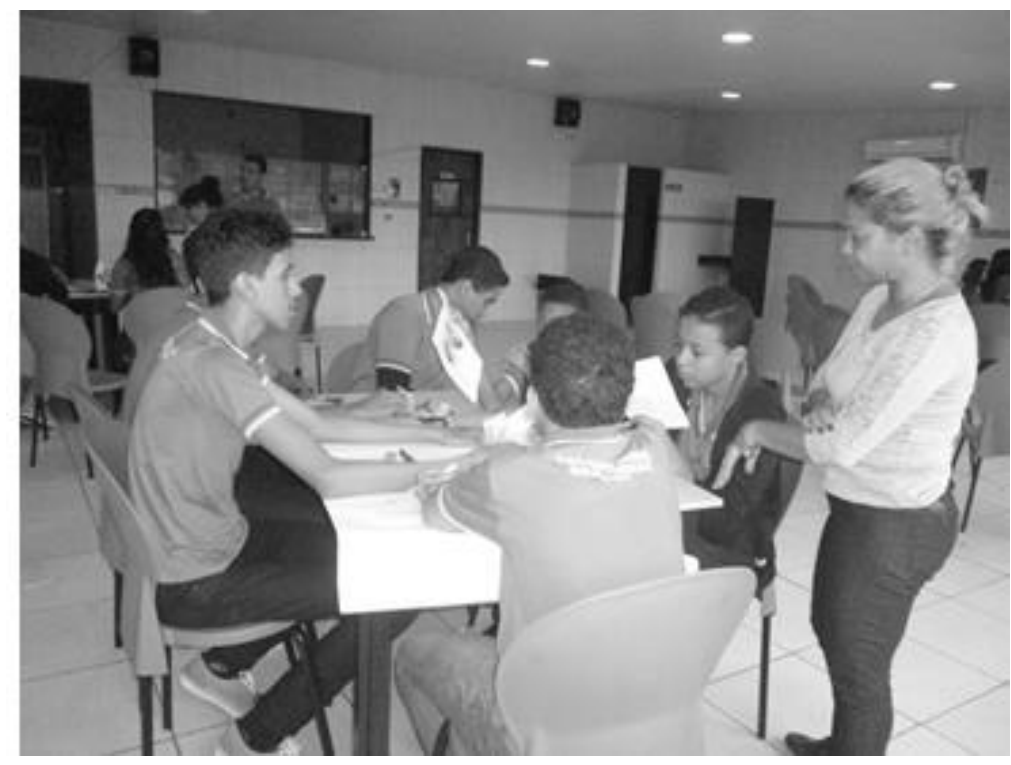

Fonte: Registro fotográfico de Misael Silva.

Com o objetivo de desenvolver no aluno habilidades e competências voltadas para a questão climática e social foi abordado ainda às ações antrópicas sobre a superfície natural através das construções de grandes cidades em planícies litorâneas que segundo Ferretti (2009), a situação se complica em função do tipo de solo existente nessas regiões, pois lá predominam solos mais úmidos, com maior teor de areia, caracterizando uma situação de alto risco. Se nas grandes cidades houve elevações e suas encostas foram ocupadas irregularmente, a catástrofe será de proporções maiores, pois com a retirada da cobertura vegetal, aliadas a declividade e fortes chuvas originam deslizamentos que "carregam" tudo o que se encontra naquela porção da encosta.

Em um segundo momento foi construído um debate baseado na leitura de um texto de Ferretti (2009) demonstrando a conjugação de situações de impermeabilização do solo, sistema hidrográfico sem manutenção (com lixo em seus canais) e precária infraestrutura urbana resulta em consequências trágicas nas áreas de riscos e de ocupação irregular. Assim, a população mais carente, tanto financeiramente quanto de oferta de serviços, tanto financeiramente quanto de oferta de serviços públicos de qualidade, é a mais vulnerável.

Durante a exibição e debate foi destacado ainda que nas áreas rurais, o excesso de chuvas provoca queda na produção agropecuária, que é afetada devido às inundações, pois os solos encharcam, impossibilitando o crescimento da espécie cultivada. Na região do semiárido do Nordeste as fortes chuvas também provocam a lixiviação. Os professores de Ciências e Geografia mencionaram as ações da La Niña sobre a ZCIT, que segundo Ferretti (2007) provoca resfriamento da superfície das porções centro e leste do Oceano Pacífico. Com o resfriamento, a pressão atmosférica tende a se elevar, 
aumentando a intensidade dos ventos alísios, provocando mais chuvas no Nordeste e seca nas regiões Sul e Sudeste.

As disciplinas de português e artes trouxeram à aula formas mais dinâmica de leituras, proporcionadas pelos mapas, gráficos, infográficos, climogramas, fluxogramas, iconográficos e imagens de satélites proporcionando relações entre imagens, símbolos e palavras (Figura 7). A aula foi interessante, pois, criou-se nos educandos a habilidade de juntar informações e assimilar a dinâmica do clima e a explicação de fenômenos de tão grande significado presentes nos objetos de interpretação citados acima.

Figura 7: Professora de Português/Artes auxiliando os alunos quanto à leitura e interpretação de infográficos.

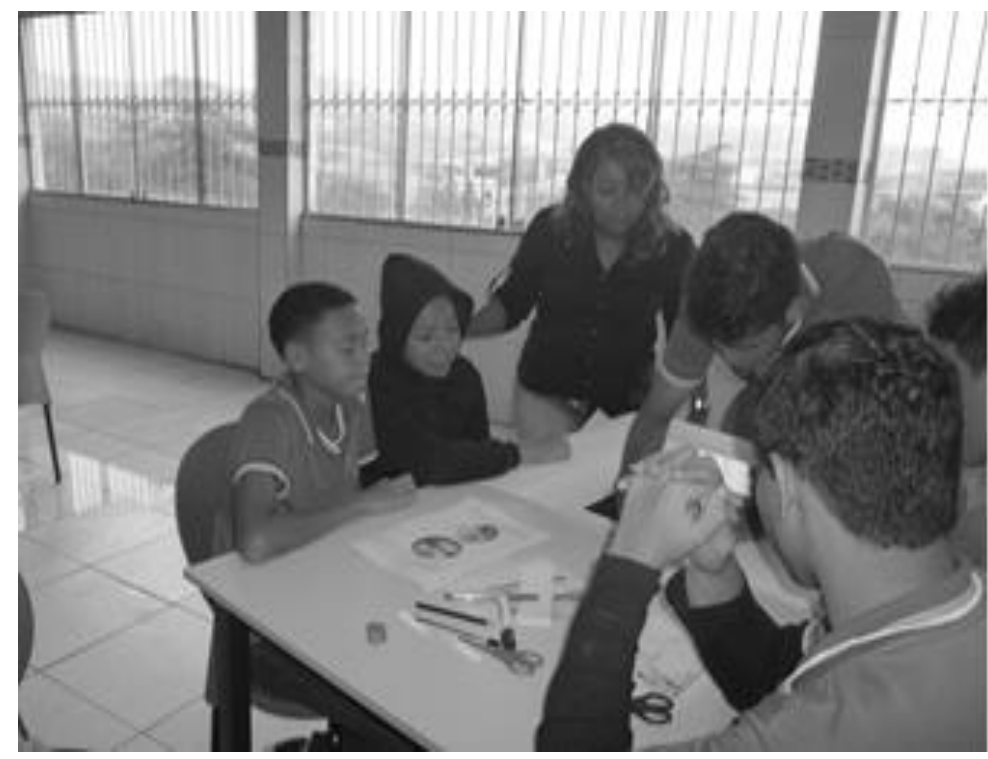

Fonte: Registro fotográfico de Misael Silva.

Durante a aula de Geografia o professor relembrou e aprofundou os conceitos de ZCIT, visto que, de forma geral, os conceitos carecem de profundidade específica. Foi relacionado suas influencias no território nacional e em especial na Região do Nordeste destacando que o excesso de chuvas segundo Ferretti (2007) é decorrente de fenômenos atmosféricos de grande escala. As consequências ocorrem pela falta de planejamento adequado na ocupação do espaço geográfico. Se esse excesso pode originar consequências catastróficas para a sociedade humana, a falta de chuvas constitui outra modalidade de problema ambiental. Quando ocorrem por um longo período de tempo e afetam uma área produtiva ou densamente ocupada, provocam graves problemas econômicos, sociais e geopolíticos. Foram abordados ainda temas como, ventos alísios, temperatura da superfície do mar TSM, força de coriolis, massas de ar, tempo, clima e precipitação, sempre os correlacionando a ZCIT. 
Após a finalização das etapas de apresentação dos professores os alunos foram divididos em equipes para confecção de um painel interativo relacionando a temática da zona de convergência intertropical e suas influências no Nordeste brasileiro (Figura 8). Construído os cartazes, os alunos puderam apresentar suas análises e conclusões sobre o papel e influências da ZCIT sobre o Nordeste e como esse sistema climático influência de forma dinâmica suas vidas (Figura 9).

Figura 8: Confecção do painel interativo relacionando a temática da ZCIT.
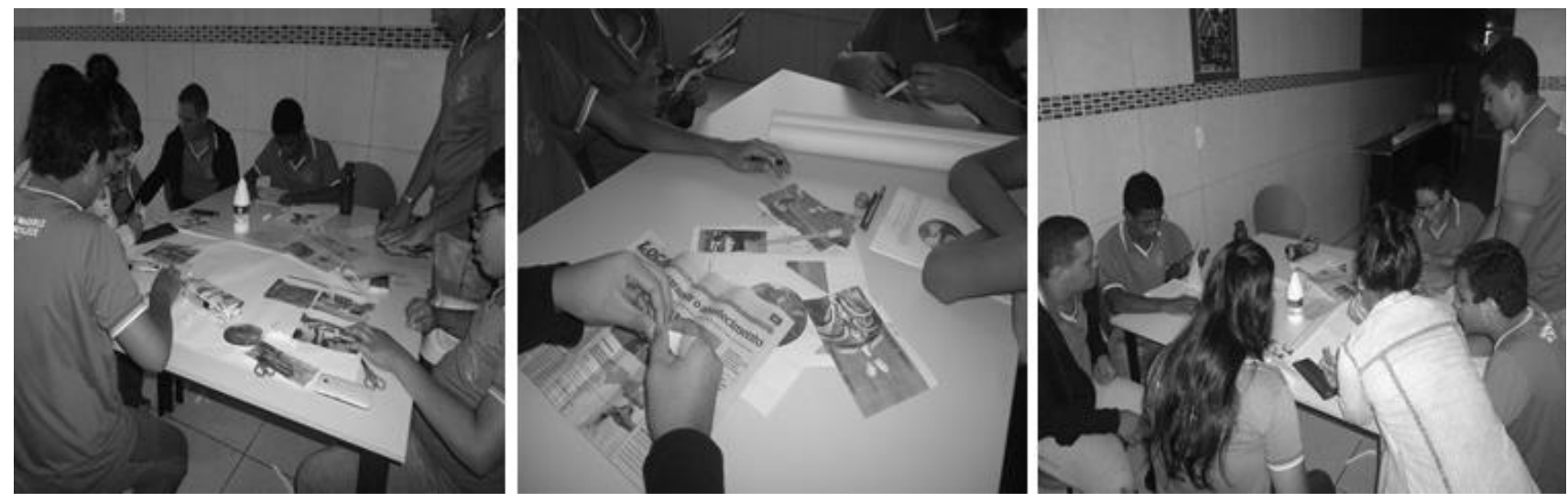

Fonte: Registro fotográfico de Misael Silva.

Figura 9: Apresentação dos conhecimentos adquiridos.
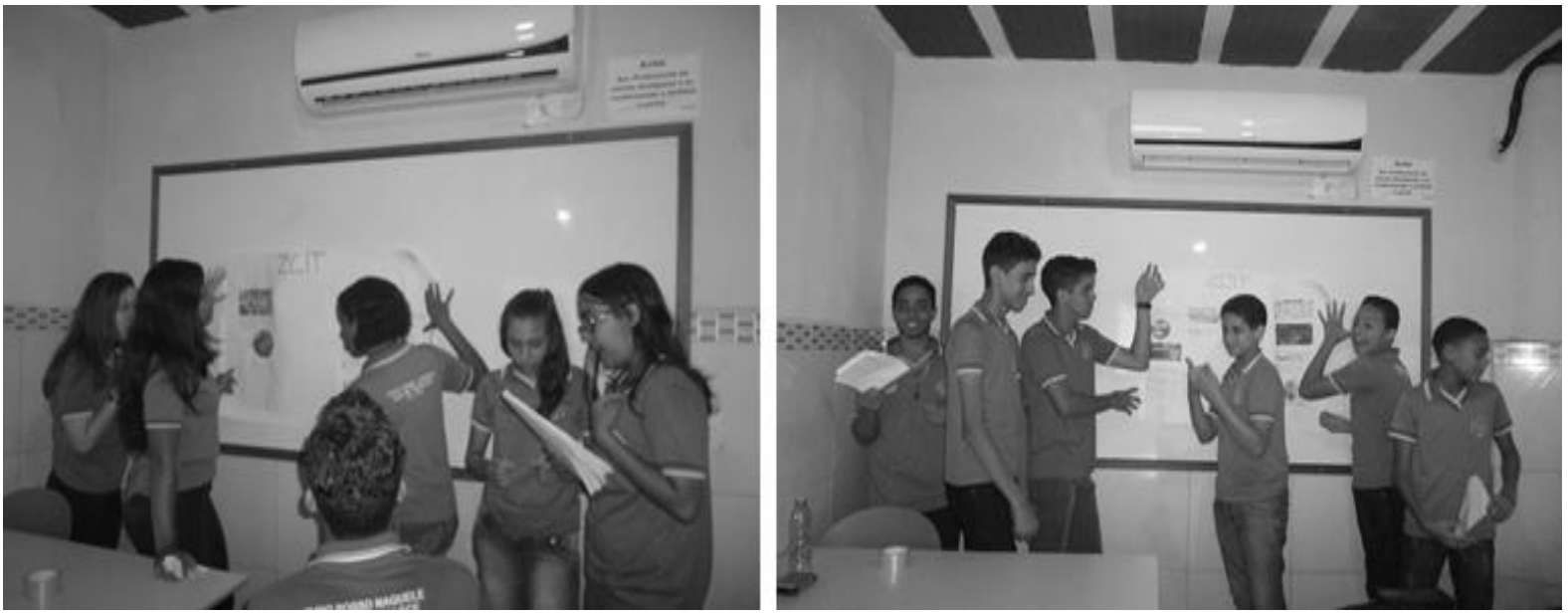

Fonte: Registro fotográfico de Misael Silva.

\section{CONCLUSÕES}

O trabalho exposto foi de grande importância para início de quebra de paradigmas e inovação no ceio escolar, visto que os ganhos com a prática aconteceram a curto e médio prazo, pois os estudantes desenvolveram, pós prática, maior interesse sobre questões climáticas em especial voltadas para o Nordeste. Vale ressaltar o comentário de alguns estudantes que passaram a entender 
melhor quando a moça do tempo do telejornal estava explicando se ocorreria ou não chuvas em determinado local, pelo simples fato de saberem interpretar as imagens ali exibidas. Logo, foi desenvolvido no aluno competências e habilidades no âmbito das interpretações de fenômenos climáticos e suas consequências para o meio antrópico, em especial a ZCIT. A prática para os professores revelou o quanto é significativo desenvolver novas posturas diante dos conhecimentos e abordagens em suas ações diárias, a fim de garantir a construção de um conhecimento globalizante e menos fragmentado como ocorre na contemporaneidade. Os discentes comprometeram-se a buscar continuamente ampliar os conhecimentos de outras áreas e colocá-las em suas aulas cotidianamente.

Portanto, a prática interdisciplinar é importante para o envolvimento e integração de conteúdos, deixando para trás a atual percepção fragmentada do conhecimento, para uma concepção como um todo, estabelecendo a superação da dicotomia entre ensino e pesquisa, a partir do apoio das diversas ciências nos diversos níveis de ensino.

\section{AGRADECIMENTOS}

Aos alunos do 9o ano, professores e coordenadores do Colégio Pentecostal pela colaboração e engajamento no projeto proposto; ao Mestrado Profissional em Rede Nacional para o Ensino de Ciências Ambientais (PROFCIAMB) e a Agência Nacional de Águas (ANA) pelo apoio e incentivo ao estudo do primeiro autor; e a Coordenação de Aperfeiçoamento de Pessoal de Nível Superior (CAPES) pela concessão da bolsa PNPD.

\section{REFERÊNCIAS}

CAVIEDES, C. N. Secas and El Niño: two simultaneous climatical hazards in South América. Proceedings of the Association of American Geography, v. 5, p. 44-49, 1972.

CIRILO, J. A. et al. O uso sustentável dos recursos hídricos em regiões semiáridas. Recife: Ed. Universitária da UFPE, 2007. 508 p.

FERRETTI, E. Geografia em ação, práticas em climatologia. Curitiba: Aymará, 2009. 143 p.

JATOBÁ, L.; LINS, R. C. Tópicos especiais de geografia física. Recife: Ed. Universitária, 1996. $104 \mathrm{p}$.
MENDONÇA. F.; DANNI-OLIVEIRA, I. M. Climatologia: noções básicas e climas do Brasil. São Paulo: Oficina de Textos, 2007. $206 \mathrm{p}$.

PHILIPPI JR., A. et al. A interdisciplinaridade em ciências ambientais. São Paulo: Signus Editora, 2000. 318 p.

PIRES, M. F. C. Reflexões sobre a interdisciplinaridade na perspectiva de integração entre as disciplinas dos cursos de graduação. Revista do IV Circuito PROGRAD: as disciplinas de seu curso estão integradas? UNESP, São Paulo, v. 1, p. 173-182, 1996. 